\title{
Polyamine inhibition of the conversion of human proacrosin to acrosin
}

\author{
R. F. Parrish, J. C. Goodpasture*, L. J. D. Zaneveld* and \\ K. L. Polakoski \\ Department of Obstetrics and Gynecology, Washington University School of Medicine, \\ St. Louis, Missouri 63110, and \\ * Department of Physiology and Biophysics, University of Illinois at the Medical Center, \\ Chicago, Illinois 63680, U.S.A.
}

\begin{abstract}
Summary. The conversion of human proacrosin to acrosin was inhibited by polyamines. The order of effectiveness was spermine $>$ spermidine $>$ cadaverine $>$ putrescine $>1,3$-diaminopropane. These results are similar to those obtained for the conversion of boar proacrosin to acrosin. Unlike the effects on boar acrosin, however, polyamines did not affect the esterolytic activity of human acrosin but had a slight stimulatory effect on the proteolytic activity of human acrosin.
\end{abstract}

\section{Introduction}

Although polyamines have been shown to be present at significant concentrations in human semen (Jänne, Hölttä, Haaranen \& Elfving, 1973; Fair, Clark \& Wehner, 1972; Weaver \& Herbst, 1958; Rosenthal \& Tabor, 1956), a physiological role for these compounds has not been firmly established. Tabor \& Rosenthal (1956) observed that the addition of spermine to motile spermatozoa obtained from the vas deferens of mice, rats, guinea-pigs and rabbits caused the spermatozoa to vibrate rapidly without forward motion. Fair et al. (1972) found a correlation between spermine concentration in the ejaculate and the motility of human spermatozoa. Besides motility, the polyamines may regulate the enzymic activity of one or more enzymes present in spermatozoa and Parrish \& Polakoski (1977) have demonstrated that polyamines stimulated the enzymic activity of boar acrosin, but inhibited the conversion of boar proacrosin to acrosin. Spermine, the polyamine present in the highest concentration (2-8 mM) in human semen, had the greatest effect in both cases. This polyamine caused a pronounced inhibition of the conversion of boar proacrosin to acrosin at $2 \mathrm{~mm}$ concentration, well within the physiological range that is present in human semen. Therefore, an investigation was undertaken to determine whether spermine and other polyamines have the same effects on the human acrosin-proacrosin system.

\section{Materials and Methods}

Spermine, spermidine, putrescine, cadaverine, $N$ - $\alpha$-benzoyl-L-arginine ethyl ester (BAEE) and $N$ $\alpha$-benzoyl-DL-arginine- $\beta$-naphthylamide were obtained from Sigma Chemical Company. 1,3Diaminopropane was purchased from Aldrich Chemical Company. Trypsin was a Worthington product. Azocoll was purchased from Calbiochem-Behring Corp. All other chemicals were the highest grade commercially available. Buffer solutions were prepared with deionized, glassdistilled water.

Partly purified proacrosin was prepared from human ejaculated spermatozoa as previously described (Goodpasture, Polakoski \& Zaneveld, 1978). Acrosin activity was measured spectrophotometrically at $253 \mathrm{~nm}$ by following the hydrolysis of BAEE at $\mathrm{pH} 8.0$ and $30^{\circ} \mathrm{C}$ in a 
$3.0 \mathrm{ml}$ reaction solution consisting of $0.05 \mathrm{M}-\mathrm{Tris}-\mathrm{HCl}, 0.05 \mathrm{M}$-calcium chloride and $0.5 \mathrm{mM}$ BAEE (Schwert \& Takenaka, 1955). A molar absorbance difference of $1150 \mathrm{M} \mathrm{cm}^{-1}$ was used to convert the change in absorbance to $\mu$ mol BAEE hydrolysed (Whitaker \& Bender, 1965). Acrosin hydrolysis of the general proteinase substrate, azocoll, was measured at $\mathrm{pH} 8.0$ in 0.1 M-Tris- $\mathrm{HCl}$ containing $10 \mathrm{~mm}$-spermine, $10 \mathrm{~mm}$-cadaverine or no added polyamine, by the general method previously described (Parrish \& Polakoski, 1977). Proacrosin was converted to acrosin by keeping the solutions on ice at $\mathrm{pH} 8.0$ in $0.1 \mathrm{M}$ - Tris- $\mathrm{HCl}$ in the presence and absence of various polyamines. This temperature was chosen because the rapid conversion of proacrosin to acrosin at room temperature precluded obtaining reliable data points for monitoring the conversion in the absence of polyamines. Also this was the temperature utilized in the study of the effect of polyamines on the conversion of boar proacrosin to acrosin (Parrish \& Polakoski, 1977). At the appropriate time intervals, an aliquot was removed from the reaction mixture, adjusted to $\mathrm{pH} 3.0$ with $1.0 \mathrm{M}-\mathrm{HCl}$ and the acrosin activity was measured. When testing the effect of polyamines on human acrosin, proacrosin was first converted to acrosin by incubation for $15 \mathrm{~min}$ in the absence of polyamines and the enzymic activity was measured as described above, with the assay solutions containing a final polyamine concentration of $10 \mathrm{~mm}$. The acrosin prepared in this manner demonstrated a single band of enzymic activity following electrophoresis at $\mathrm{pH} 4.3$ (Brewer \& Ashworth, 1969) and staining for $N$ - $\alpha$-benzoyl-DL-arginine$\beta$-naphthylamide hydrolysis (Garner \& Cullison, 1974; Polakoski \& Parrish, 1977). The relative migration of this acrosin preparation was 0.63 when trypsin hydrolysis of $N$ - $\alpha$-benzoyl-DLarginine- $\beta$-naphthylamide was used as the standard (i.e. the migration of trypsin $=1.0$ ).

\section{Results}

A concentration of $2 \mathrm{mM}$-spermine was chosen for the initial experiments. The data in Text-fig. 1 demonstrate that this amount of spermine significantly delayed the conversion of human proacrosin to acrosin. The effect of $2 \mathrm{mM}$, as well as $10 \mathrm{~mm}$ concentrations of spermine and several other polyamines was subsequently investigated. It can be further seen from Text-fig. 1 that a 15 -min incubation at $\mathrm{pH} 8.0$ in $0.1 \mathrm{M}$-Tris- $\mathrm{HCl}$ on ice was sufficient for full conversion of human proacrosin to acrosin. Therefore, a simple method to compare the effect of various polyamines was to determine the acrosin activity present after a 15-min incubation of proacrosin in the absence and presence of the given polyamines. The results of these experiments are shown in Table 1. Some inhibition was noted for all polyamines at a concentration of $2 \mathrm{~mm}$, but a much

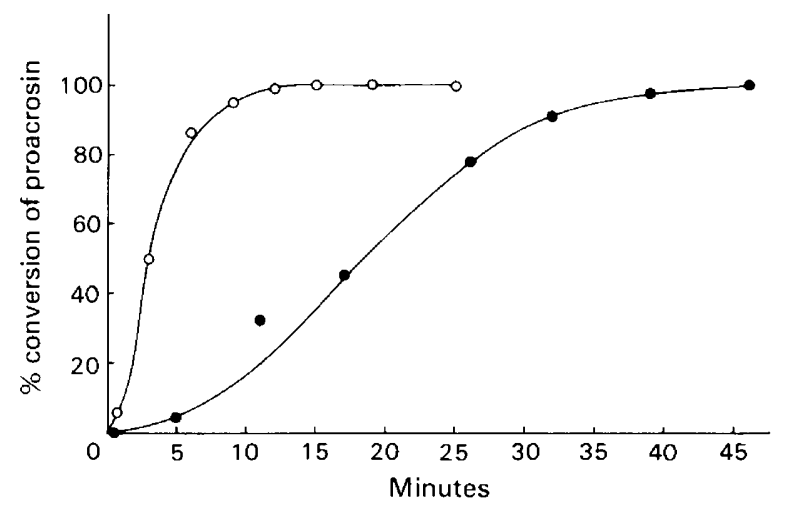

Text-fig. 1. Conversion of proacrosin to acrosin in the presence and absence of spermine. The reaction mixture at $\mathrm{pH} 8.0$ and $0^{\circ} \mathrm{C}$ consisted of proacrosin and $0.1 \mathrm{M}$-Tris- $\mathrm{HCl}(\mathrm{O})$ or $0.1 \mathrm{M}$ Tris- $\mathrm{HCl}$ with $0.002 \mathrm{M}$-spermine (O). At the indicated times an aliquot was removed, adjusted to $\mathrm{pH} 3 \cdot 0$, and the acrosin activity measured as described in the 'Methods'. 
greater inhibition was seen when the polyamine concentration was increased to $10 \mathrm{mM}$. At this concentration of spermine, no conversion of proacrosin to acrosin occurred. Control experiments utilizing sodium chloride indicated that the inhibitory effect of the polyamines on the proacrosin conversion was not the result of the increased ionic strength of the polyamine-containing buffers.

Table 1. The effect of polyamines at 2 or $10 \mathrm{~mm}$ on the conversion of human proacrosin to acrosin

\begin{tabular}{lcc}
\hline \multirow{2}{*}{$\begin{array}{c}\text { Polyamine } \\
\text { added }\end{array}$} & \multicolumn{2}{c}{$\%$ Conversion of proacrosin } \\
\cline { 2 - 3 } \multicolumn{1}{c}{ None } & $2 \mathrm{mM}$ & $10 \mathrm{mM}$ \\
\hline Spermine & 100 & 100 \\
Spermidine & 36 & 0 \\
Cadaverine & 65 & 7 \\
Putrescine & 76 & 12 \\
1,3-Diaminopropane & 87 & 27 \\
\hline
\end{tabular}

Acrosin activity was measured after a 15-min incubation of proacrosin in $0.1 \mathrm{M}$-Tris- $\mathrm{HCl}, \mathrm{pH} 8.0$, with polyamines at the indicated concentrations. Values are expressed as the mean of duplicate determinations.

The sigmoidal time course for the appearance of acrosin activity from proacrosin is characteristic of systems in which the product (acrosin) reacts with the substrate (proacrosin) to produce more product (Kassell \& Kay, 1973). It was therefore necessary to determine if spermine and the other polyamines inhibited the enzymic activity of acrosin. A concentration of $10 \mathrm{~mm}$-polyamine was used for the assay because this corresponded to the highest concentration of polyamine employed in the proacrosin conversion experiments (Table 1). The data in Tables 2

Table 2. The effect of polyamines on the esterolytic activity of human acrosin

\begin{tabular}{lc}
\hline Polyamine added & $\begin{array}{c}\text { Enzymic activity } \\
(\mu \mathrm{mol} / \mathrm{min}) \times 10^{2}\end{array}$ \\
\hline None & 9.4 \\
Spermine & 9.7 \\
Spermidine & 9.7 \\
Cadaverine & 9.3 \\
Putrescine & 9.7 \\
1,3-Diaminopropane & 9.7 \\
\hline
\end{tabular}

Reaction mixture at $\mathrm{pH} 8.0$ consisted of 0.1 $\mathrm{M}$-Tris- $\mathrm{HCl}, \quad 0.5 \mathrm{mM}-\mathrm{BAEE}$, and the polyamines indicated at a concentration of $10 \mathrm{~mm}$. Values are expressed as the mean of duplicate determinations.

and 3 demonstrate that, at this concentration, the polyamines had no inhibitory effect on either the esterolytic or proteolytic activity of human acrosin. In fact, a slight stimulation of the proteolytic activity was observed. This suggests that the polyamine inhibition of proacrosin conversion resulted from an interaction between the zymogen and the polyamines and not from an inhibition of the activity of acrosin. 
Table 3. The effect of polyamines on the proteolytic activity of human acrosin

\begin{tabular}{lc}
\hline Polyamine added & $\begin{array}{c}\text { Relative azocoll } \\
\text { digestion (\%) }\end{array}$ \\
\hline None & 100 \\
Spermine & 115 \\
Cadaverine & 109 \\
\hline \multicolumn{1}{c}{ Reaction mixture at $\mathrm{pH} 8 \cdot 0$ consisted of } \\
$0.1 \mathrm{M}$-Tris-HCl, azocoll $(10 \mathrm{mg} / \mathrm{ml})$, and the \\
polyamines indicated at a concentration of \\
10 mM. Values are expressed as the mean of \\
triplicate determinations.
\end{tabular}

\section{Discussion}

The results demonstrate that polyamines, in particular spermine, inhibit the conversion of human proacrosin to acrosin. There also appears to be a correlation between the size and/or the net charge of the polyamines and their effect on the conversion process. Spermine, the largest polyamine and that with the greatest positive charge, produced the greatest inhibition, while the smallest polyamine, 1,3-diaminopropane, produced the least inhibition. Increasing the separation (methylene groups) of positive nitrogens in the polyamine also resulted in increased inhibition, i.e., cadaverine ( 5 methylene groups) $>$ putrescine ( 4 methylene groups) $>1,3$-diaminopropane (3 methylene groups).

The present report emphasizes the need for comparative biochemical studies between various species of interest, because the results demonstrate differences as well as similarities between the proacrosin-acrosin system of boar and human spermatozoa. Unlike that of boar acrosin, the esterolytic activity of human acrosin was not affected by polyamines although stimulation of the proteolytic activity by polyamines occurs for both. As with boar proacrosin, polyamines inhibited the conversion of human proacrosin to acrosin and there was an apparent correlation between the size of the polyamine and the magnitude of its effect on the conversion process.

The physiological significance of the observations reported in this paper are presently difficult to evaluate. However, the polyamines do inhibit the in-vitro conversion of human proacrosin to acrosin and significant amounts of seminal plasma-derived spermine remain bound to the spermatozoa even after washing (Pulkkinen, Kanerva, Elfving \& Jänne, 1975). Although the actual presence of spermine and the other polyamines in the acrosome of the spermatozoon has not been established, these results at least indicate that polyamines have the potential to modulate the in-vivo conversion of human proacrosin to acrosin. More research will be required to determine if polyamines do indeed have a physiological function in the conversion of proacrosin to acrosin, a reaction that is presently thought to be critical for successful reproduction (McRorie \& Williams, 1974).

This research was supported by National Institutes of Health Grants HD 09422 and 09868 and by a grant from the Rockefeller Foundation.

\section{References}

Brewer, J.M. \& Ashworth, R.B. (1969) Disc electrophoresis. J. Chem. Educ. 46, 41-45.

Fair, W.R., Clark, R.B. \& Wehner, N. (1972) A correlation of seminal polyamine levels and semen analysis in the human. Fert. Steril. 23, 38-42.
Garner, D.L. \& Cullison, R.F. (1974) Partial purification of bovine acrosin by affinity chromatography. $J$. Chromatog. 92, 445-449.

Goodpasture, J.C., Polakoski, K.L. \& Zaneveld, LJ.D. (1978) The proacrosin, acrosin, and acrosin inhibitor 
system of human spermatozoa. Proc. Am. Soc. Andrology, Nashville, Tennessee, p. 33, Abstr.

Jänne, J., Hölttä, E., Haaranen, P. \& Elfving, K. (1973) Polyamines and polyamine-metabolizing enzyme activities in human semen. Clin. Chim. Acta 48, 393-401.

Kassell, B. \& Kay, J. (1973) Zymogens of proteolytic enzymes. Science, N.Y. 180, 1022-1027.

McRorie, R.A. \& Williams, W.L. (1974) Biochemistry of mammalian fertilization. Ann. Rev. Biochem. 43, 777-803.

Parrish, R.F. \& Polakoski, K.L. (1977) Effect of polyamines on the activity of acrosin and the activation of proacrosin. Biol. Reprod. 17, 417-422.

Polakoski, K.L. \& Parrish, R.F. (1977) Boar proacrosin: purification and preliminary activation studies of proacrosin isolated from ejaculated boar sperm. J. biol. Chem. 252, 1888-1894.

Pulkkinen, P., Kanerva, S., Elfving, K. \& Jänne, J.
(1975) Association of spermine and diamine oxidase activity with human spermatozoa. $J$. Reprod. Fert. 43, 49-55.

Rosenthal, S.M. \& Tabor, C.W. (1956) The pharmacology of spermine and spermidine. Distribution and excretion. J. Pharmac. exp. Ther. 116, 131-138.

Schwert, G.W. \& Takenaka, Y. (1955) A spectrophotometric determination of trypsin and chymotrypsin. Biochim. Biophys. Acta 16, 570-575.

Tabor, C.W. \& Rosenthal, S.M. (1956) Pharmacology of spermine and spermidine. Some effects on animals and bacteria. J. Pharmac. exp. Ther. 116, 139-155.

Weaver, R.H. \& Herbst, E.J. (1958) Metabolism of diamines and polyamines in microorganisms. J. biol. Chem. 231, 637-646.

Whitaker, J.R. \& Bender, M.L. (1965) Kinetics of papain-catalyzed hydrolysis of $a-N$-benzoyl-Larginine ethyl ester and $\alpha-N$-benzoyl-L-arginamide. $J$. Am. Chem. Soc. 87, 2728-2737.

Received 26 February 1979 